\title{
Kombinasi Pengaruh Media Tanam Akar Pakis dan Arang Sekam Terhadap Perkecambahan dan Pertumbuhan Bibit Eucalyptus pellita L. Muell.
}

\author{
Mufti Perwira Putra ${ }^{1}$, Muli Edwin ${ }^{2}$ \\ 1,2 Program Studi Kehutanan, Sekolah Tinggi Pertanian Kutai Timur, Sangatta, Kutai \\ Timur, Kalimantan Timur \\ 1Email : muftiotie@gmail.com \\ Email : edwin.kutim@gmail.com
}

\begin{abstract}
The research had been conducted for 3 months from February to April 2016. The research was located in the nursery of PT Surya Hutani Jaya, Puan Cepak Village, Muara Kaman Sub-district, Kutai Kartanegara Regency. The aims of this research were to determine the influence of planting media on seeds germination and seedlings growth of Eucalyptus pellita L. Muell. and to determine the best composition of planting media for the growth of E. pellita seedlings. The research was designed using nonfactorial in Completely Randomized Design (RAL) with 5 levels of fern root and charcoal husk as planting media, each of which was repeated 4 times. The treatments were $M 0=100 \%$ fern root, $M 1=90 \%$ fern root $+10 \%$ charcoal husk, $M 2=$ fern root $80 \%+20 \%$ charcoal husk, M3 $=70 \%$ fern root $+30 \%$ charcoal husk, and M4 $=$ fern root $60 \%+40 \%$ charcoal husk. Results of the research showed that the treatments had no significant effect on E. pellita seed germination, seedlings height, leaf number, stem diameter, compactness of roots, and pest and disease attack. Then all the given treatments were same good for seed germination and growth of E. pellita seedlings. Keywords: planting medium, fern root, husk, seedling, Eucalyptus pellita
\end{abstract}

\begin{abstract}
ABSTRAK
Penelitian telah dilaksanakan selama 3 bulan mulai bulan Febuari sampai April 2016. Penelitian ini berlokasi di persemaian PT Surya Hutani Jaya, Desa Puan Cepak, Kecamatan Muara Kaman, Kabupaten Kutai Kartanegara. Penelitian bertujuan untuk mengetahui pengaruh media tanam terhadap perkecambahan benih dan pertumbuhan bibit Eucalyptus pellita L. Muell. dan mengetahui komposisi media tanam yang terbaik untuk pertumbuhan bibit $E$. pellita. Penelitian disusun menggunakan pola nonfaktorial di dalam Rancangan Acak Lengkap (RAL) dengan 5 taraf perlakuan media tanam akar pakis dan arang sekam yang masing-masing diulang 4 kali. Perlakuan yang diberikan adalah $\mathrm{M} 0=$ akar pakis $100 \%, \mathrm{M} 1=$ akar pakis $90 \%+$ arang sekam $10 \%, \mathrm{M} 2$ = akar pakis $80 \%+$ arang sekam $20 \%, \mathrm{M} 3=$ akar pakis $70 \%+$ arang sekam $30 \%$, dan $\mathrm{M} 4$ = akar pakis $60 \%+$ arang sekam $40 \%$. Hasil penelitian menunjukkan, bahwa perlakuan berpengaruh tidak signifikan terhadap perkecambahan benih E. pellita, tinggi bibit, jumlah daun, diameter batang, kekompakan akar serta serangan hama dan penyakit. Jadi perlakuan yang diberikan sama baiknya untuk perkecambahan benih dan pertumbuhan bibit $E$. pellita.
\end{abstract}

Kata kunci: media tanam, akar pakis, sekam, bibit, Eucalyptus pellita

\section{Pendahuluan}

Eucalyptus pellita F. Muell adalah salah satu jenis cepat tumbuh yang mempunyai potensi untuk dikembangkan dalam Hutan Tanaman Industri ( $\mathrm{HTI})$ karena sifatnya yang mudah menyesuaikan diri dan kayunya dapat digunakan untuk bahan pulp (bubur kertas). Jenis ini merupakan salah satu spesies endemik Indonesia yang tumbuh di Papua pada 
ketinggian di atas $800 \mathrm{~m}$ dpl dengan curah hujan 900 - $2100 \mathrm{~mm} /$ tahun (Leksono, 2001). Penggunaan media tumbuh yang tepat dapat mendukung upaya percepatan budidaya $E$. pellita dalam pembangunan $\mathrm{HTI}$..

Media tumbuh yang baik adalah media yang mampu menyediakan air dan unsur hara dalam jumlah cukup bagi pertumbuhan bibit. Hal ini dapat ditemukan pada tanah dengan tata udara dan air yang baik, mempunyai agregat mantap, kemampuan menahan air yang baik dan ruang untuk perakaran yang cukup (Gardner dan Mitchell, 1991). Menurut Kuswanto (1996), penyemaian benih untuk tanaman tertentu harus dipilih media perkecambahan yang cocok agar kemampuan berkecambah benih menunjukkan kondisi benih sesungguhnya. Fungsi utama media perkecambahan adalah untuk memenuhi kebutuhan benih akan air dan unsur hara yang diperlukan selama proses perkecambahan dan pertumbuhan bibit. Mutu bibit di persemaian di antaranya dipengaruhi secara langsung oleh kondisi media tempat tumbuhnya. Media tumbuh mempunyai peranan penting dalam memenuhi berbagai kebutuhan hidup tanaman yaitu memberi dukungan mekanik menjadi tempat berjangkarnya akar, menyediakan ruang untuk partumbuhan dan perkembangan akar, serta menyediakan udara untuk respirasi, air dan hara yang dibutuhkan oleh tanaman (Putri dan Djam'an, 2004). Adanya alternatif pencampuran media tumbuh baru untuk pembibitan benih E. pellita diharapkan dapat meningkatkan hasil pertumbuhan bibit $E$. pellita yang baik serta media tumbuh yang ringan sehingga mudah dalam transportasi bibit. Selain itu, dengan pencampuran media tumbuh tersebut bisa mengurangi serangan penyakit yang umumnya menyerang di persemaian.

Faktor-faktor yang mempengaruhi pertumbuhan tanaman terdiri atas faktor internal dan faktor eksternal. Faktor internal merupakan faktor yang terdapat pada benih atau tanaman itu sendiri. Faktor eksternal merupakan faktor yang terdapat di luar benih atau tanaman, salah satu yang mempengaruhi pertumbuhan yaitu media tanam. Berbagai jenis media tanam dapat digunakan, tetapi pada prinsipnya menggunakan media tanam yang mampu menyediakan nutrisi, air, dan oksigen bagi tanaman. Penggunaan media yang tepat akan memberikan pertumbuhan yang maksimal bagi tanaman (Fahmi, 2014). Berdasarkan uraian di atas, tujuan penelitian ini adalah:

1. Mengetahui pengaruh media tanam terhadap perkecambahan dan pertumbuhan bibit E. pellita.

2. Mengetahui komposisi media tanam yang terbaik bagi pertumbuhan bibit E. pellita.

\section{Metode Penelitian}

Penelitian telah dilaksanakan selama 3 bulan mulai bulan Febuari - April 2016. Tempat penelitian berlokasi di persemaian nursery PT. Surya Hutani Jaya, Desa Puan Cepak, Kecamatan Muara Kaman, Kabupaten Kutai Kartanegara. Bahan yang digunakan pada penelitian ini yaitu biji E. pellita yang diambil dari R\&D Center Surya Hutani Jaya 
(SHJ) dan media tanam (akar pakis dan arang sekam), pupuk TSP, dan dolomit. Peralatan yang digunakan meliputi: potongan drum, cangkul, tube, rak, baki, penjepit, stick, gunting, pita, sprayer, penggaris, kaliper, tally sheet, kamera.

\subsection{Rancangan Penelitian}

Penelitian ini dirancang menggunakan pola Rancangan Acak Lengkap (RAL) nonfactorial dengan 5 taraf perlakuan media tanam yang masing-masing perlakuan diulang sebanyak 4 kali sehingga terdapat 20 satuan petak penelitian. Adapun taraf perlakuan media tanam, terdiri atas :

$\mathrm{MO}=$ akar pakis (kontrol)

M1 = akar pakis $90 \%+$ arang sekam $10 \%$

M2 = akar pakis $80 \%+$ arang sekam $20 \%$

M3 = akar pakis $70 \%+$ arang sekam 30\%

M4 = akar pakis $60 \%+$ arang sekam $20 \%$

\subsection{Prosedur Pelaksanaan Penelitian}

Pembuatan Arang Sekam

Proses pembuatan arang sekam dilakukan dengan menyangrai sekam padi mentah di dalam potongan drum di atas tungku sambil diaduk-aduk hingga sekam menjadi arang. Arang sekam lalu dikeluarkan dari drum dan disiram air untuk pendinginan sambil diaduk merata agar proses pendinginan dapat sempurna sehingga tidak ada lagi arang sekam yang masih membara.

Persiapan Benih dan Media Tanam

Benih E. pellita diperoleh dari R\&D Center PT. Surya Hutani Jaya (SHJ). Media tanam akar pakis dicacah hingga kecil-kecil, selanjutnya dicampur dengan arang sekam dengan komposisi perbandingan sesuai perlakuan. Media tanam kemudian diaduk sampai merata dan dimasukkan ke dalam tube yang terbuat dari Poly-propylene dengan ukuran (panjang $x$ lebar $x$ tinggi) $3,5 \mathrm{~cm} \times 3,5 \mathrm{~cm} \times 10 \mathrm{~cm}$ setiap tube. Pengisian tube dilakukan hingga penuh dengan kondisi tidak terlalu padat dan tidak terlalu longgar dengan cara menghentakkan tube dari atas ke bawah. Tube yang telah berisi media tanam selanjutnya disusun pada rak yang telah disediakan.

Penyemaian Benih

Wadah semai berupa rak polytube yang telah dilapisi sarlon yang dipotong sebagian menutupi lubang rak dan telah diisi media tanam berupa akar pakis sesuai perlakuan. Bak tabur ditempatkan tidak bersentuhan langsung dengan lantai agar kelebihan air dapat keluar dari bak. Bak tabur diisi media tanam hingga merata lalu disiram air. Benih kemudian disebar/ditabur secara merata di atas permukaan media. Benih selanjutnya ditutup pasir dan disiram menggunakan sprayer hingga basah namun tidak sampai becek. Bak semai ditempatkan dibawah naungan agar terlindung dari hujan 
namun tetap mendapatkan sinar matahari. Persemaian disiram setiap hari pagi dan sore sesuai kondisi cuaca. Persemaian dipasangi label sesuai perlakuan.

Penyapihan Bibit

Setelah benih berkecambah yaitu usia 10 hari setelah semai (HSS), dilakukan penyapihan. Penyapihan dilakukan secara hati-hati ke dalam tube agar bibit tidak rusak. Media tanam terlebih dahulu disiram untuk memudahkan pengangkatan bibit dari media tanam.

Pemeliharaan Bibit

Proses pemeliharaan bibit dilakukan meliputi penyiraman, pemupukan, penyiangan, dan penjarangan.

a. Penyiraman dilakukan secara rutin setiap hari pagi dan sore. penyiraman menggunakan misting/fogger sehinga penyiraman yang dihasilkan memberikan efek pengabutan.

b. Pemupukan dilakukan sebanyak 4 kali menggunakan pupuk NPK 16:16:16 dan TSP, yaitu pada saat umur bibit $25,35,45$, dan 55 hari setelah tanam. Waktu pemupukan dilakukan pagi hari mulai pukul 06.30-09.00 atau sore hari pukul 15.00-18.00. Selengkapnya dosis pemupukan sebagaimana tertera pada Tabel 1.

Tabel 1. Jadwal dan Dosis pemupukan

\begin{tabular}{|c|c|c|c|}
\hline $\begin{array}{l}\text { Umur bibit } \\
\text { (hari) }\end{array}$ & Jenis Pupuk & Dosis (g/l) & Aplikasi \\
\hline 25 & $\begin{array}{c}\text { NPK 16:16:16 } \\
\text { TSP } 45 \%\end{array}$ & $\begin{array}{l}10 \mathrm{~g} / \mathrm{l} \\
10 \mathrm{~g} / \mathrm{l}\end{array}$ & $\begin{array}{c}\text { Pupuk dilarutkan } \\
\text { dalam air, disiramkan }\end{array}$ \\
\hline 35 & $\begin{array}{l}\text { NPK } 16: 16: 16 \\
\text { TSP } 45 \%\end{array}$ & $\begin{array}{l}15 \mathrm{~g} / \mathrm{l} \\
10 \mathrm{~g} / \mathrm{l}\end{array}$ & $\begin{array}{l}\text { pada bibit dengan } \\
\text { embrat }\left(1 \mathrm{It} / \mathrm{m}^{2}\right) \text { dan }\end{array}$ \\
\hline 45 & $\begin{array}{l}\text { NPK } 16: 16: 16 \\
\text { TSP } 45 \%\end{array}$ & $\begin{array}{l}20 \mathrm{~g} / \mathrm{l} \\
20 \mathrm{~g} / \mathrm{l}\end{array}$ & $\begin{array}{l}\text { dilakukan pemilasan } \\
\text { dengan air bersih }\end{array}$ \\
\hline 55 & $\begin{array}{c}\text { NPK 16:16:16 } \\
\text { TSP } 45 \%\end{array}$ & $\begin{array}{l}20 \mathrm{~g} / \mathrm{l} \\
20 \mathrm{~g} / \mathrm{l}\end{array}$ & \\
\hline
\end{tabular}

Seleksi dan Penjarangan

Seleksi dilakukan sebanyak dua kali. Pada seleksi pertama bibit yang mati dibuang. Sedangkan, pada seleksi kedua dilakukan pemotongan $50 \%$ cabang, pelabelan dan pemindahan bibit ke open area.

\subsection{Metode Pengambilan Data}

Pengambilan data dilakukan setiap 15 hari sekali, dimulai umur 30 hari setelah sapih (HSS). Data yang diperoleh dimasukkan dalam Tabel Tally Sheet. Adapun datadata yang diambil, meliputi:

1. Tinggi Bibit $(\mathrm{Cm})$, diukur menggunakan penggaris dari pangkal batang sampai ujung pucuk tertinggi.

2. Jumlah Daun (Helai), di hitung setiap helainya daun yang membetuk daun sempurna

3. Diameter batang $(\mathrm{Cm})$, diukur menggunakan kaliper. 
Data hasil pengukuran dan pengamatan, dianalisis dengan menggunakan Analisis Sidik Ragam (ANSIRA) menurut Hanafiah (2010), seperti disajikan pada Tabel 2.

Tabel 2. Analisis Sidik Ragam

\begin{tabular}{cccccc}
\hline $\begin{array}{c}\text { Sumber } \\
\text { Keragaman }\end{array}$ & $\begin{array}{c}\text { Derajad } \\
\text { Bebas }\end{array}$ & $\begin{array}{c}\text { Jumlah } \\
\text { Kuadrat }\end{array}$ & $\begin{array}{c}\text { Kuadrat } \\
\text { Tengah }\end{array}$ & F.Hitung & \multicolumn{2}{c}{ F.Tabel } \\
\cline { 6 - 7 } $\begin{array}{c}\text { Perlakuan } \\
\text { Galat }\end{array}$ & $(\mathrm{t}-1)=\mathrm{v} 1$ & $\mathrm{JKP}$ & $\mathrm{JKP} / \mathrm{v} 1$ & $\mathrm{KTP} / \mathrm{KT} T_{\mathrm{n}}$ & (v1, v2) \\
\hline Total & $\mathrm{rt} 1=\mathrm{v} 2$ & $\mathrm{JKG}$ & $\mathrm{JKG} / \mathrm{v} 5$ & $\mathrm{KTI} / \mathrm{KTG}$ & \\
\hline
\end{tabular}

Bila hasil sidik ragam berbeda nyata ( $\mathrm{F}$ hitung $>\mathrm{F}$ tabel $5 \%$ ) atau berbeda sangat nyata ( $\mathrm{F}$ hitung $>\mathrm{F}$ tabel $1 \%$ ), maka untuk membandingkan dua rata-rata perlakuan digunakan Uji Duncan pada taraf 5\% (Hanafiah, 2010).

\section{Hasil dan Pembahasan}

\subsection{Tinggi Bibit $(\mathrm{Cm})$}

\section{Tinggi Bibit Umur 30 Hari Setelah Sapih (HSS)}

Hasil analisis keragaman, menunjukkan bahwa perlakuan media tanam akar pakis dan arang sekam berpengaruh tidak nyata terhadap rata-rata tinggi bibit $E$. pellita pada umur 30 hari. Pengaruh media tanam terhadap tinggi bibit disajikan pada Tabel 3.

Tabel 3. Pengaruh media tanam terhadap rata-rata tinggi bibit Eucalyptus pellita umur 30 HSS

Mo (akar pakis $100 \%)$ Media Tanam

(akar pakis $90 \%$ + arang sekam $10 \%$

M2 (akar pakis $80 \%$ + arang sekam 20\%) $\quad 10,28$

M3 (akar pakis 70\% + arang sekam 30\%) $\quad 10,40$

M4 (akar pakis $60 \%$ + arang sekam $40 \%$ ) 10,02

Pada umur 30 HSS, rata-rata tinggi bibit tertinggi terdapat pada akar pakis $100 \%$, yaitu $12,4 \mathrm{~cm}$. Tetapi karena dari hasil uji statistik menunjukkan tidak ada perbedaan signifikan antar perlakuan, maka perlakuan yang diberikan tersebut sama baiknya. Hal ini, diduga pertumbuhan selain dipengaruhi oleh faktor fisiologis, juga dipengaruhi oleh faktor media tanam yang mampu menyediakan kebutuhan unsur hara, air, dan udara dalam menunjang proses pertumbuhan bibit tanaman. Sejalan yang dikemukakan Fahmi (2014), bahwa faktor-faktor yang mempengaruhi pertumbuhan tanaman terdiri atas faktor internal dan faktor eksternal. Faktor internal merupakan faktor yang terdapat pada benih atau tanaman itu sendiri. Faktor eksternal merupakan faktor yang terdapat di luar benih atau tanaman, salah satu yang mempengaruhi pertumbuhan yaitu media tanam.

\section{Tinggi Bibit Umur 45 Hari Setelah Sapih (HSS)}

Hasil analisis keragaman, menunjukkan bahwa perlakuan media tanam akar pakis dan arang sekam berpengaruh tidak nyata terhadap rata-rata tinggi bibit E. pellita pada umur 45. Pengaruh media tanam terhadap tinggi bibit selengkapnya disajikan pada Tabel 4. 
Tabel 4. Pengaruh media tanam terhadap rata-rata tinggi bibit $E$. pellita umur 45 HSS

\begin{tabular}{cc}
\hline Media Tanam & Tinggi Bibit $(\mathbf{C m})$ \\
\hline Mo (akar pakis 100\%) & 24,16 \\
M1 (akar pakis 90\% + arang sekam 10\%) & 19,25 \\
M2 (akar pakis 80\% + arang sekam 20\%) & 19,44 \\
M3 (akar pakis 70\% + arang sekam 30\%) & 21,12 \\
M4 (akar pakis 60\% + arang sekam 40\%) & 15,06 \\
\hline
\end{tabular}

Pada umur 45 HSS, rata-rata tinggi bibit tertinggi terjadi pada akar pakis $100 \%$, yaitu $24,16 \mathrm{~cm}$, tetapi karena dari hasil uji statistik tidak ada perbedaan signifikan antar perlakuan, maka perlakuan yang diberikan sama baiknya. Hal ini, diduga perlakuan media tanam memiliki kemampuan yang sama dalam menunjang pertumbuhan akar bibit. Diduga, media tanam akar pakis tanpa campuran arang sekam lebih memiliki kemampuan menyediakan kondisi lingkungan media yang mampu menunjang pertumbuhan bibit.

\section{Tinggi Bibit Umur 60 Hari Setelah Sapih (HSS)}

Hasil analisis keragaman, menunjukkan bahwa perlakuan media tanam akar pakis dan arang sekam berpengaruh tidak nyata terhadap rata-rata tinggi bibit $E$. pellita pada umur 60 hari. Pengaruh media tanam akar pakis tinggi bibit selengkapnya disajikan pada Tabel 5.

Tabel 5. Pengaruh media tanam terhadap rata-rata tinggi bibit E. pellita umur $60 \mathrm{HSS}$

\begin{tabular}{lr}
\hline Media Tanam & Tinggi Bibit \\
\hline Mo (akar pakis 100\%) & 32,94 \\
M1 (akar pakis 90\%+ arang sekam 10\%) & 25,20 \\
M2 (akar pakis 80\% + arang sekam 20\%) & 28,83 \\
M3 (akar pakis 70\% + arang sekam 30\%) & 28,74 \\
M4 (akar pakis 60\% + arang sekam 40\%) & 27,31
\end{tabular}

Pada umur 60 HSS, rata-rata tinggi bibit tertinggi terjadi pada akar pakis $100 \%$, yaitu 32,94 cm, tetapi karena dari hasil uji statistik tidak ada perbedaan signifikan antar perlakuan, maka perlakuan yang diberikan sama baiknya. Akar pakis dapat menciptakan kondisi lingkungan tumbuh yang baik sehingga pertumbuhan tanaman dapat berjalan dengan baik pula. Sebagaimana dikemukakan Muliawan (2009), bahwa media tumbuh yang baik mengandung unsur hara yang cukup, bertekstur ringan, dan dapat menahan air, serta kemasaman media optimal bagi pertumbuhan tanaman sehingga menciptakan kondisi yang dapat menunjang pertumbuhan tanaman

\subsection{Jumlah Daun (Helai)}

\section{Jumlah Daun Umur 30 Hari Setelah Sapih (HSS)}

Hasil analisis keragaman, menunjukkan bahwa perlakuan media tanam akar pakis dan arang sekam berpengaruh tidak nyata terhadap rata-rata jumlah daun bibit pada umur 30 hari. Pengaruh media tanam akar pakis terhadap rata-rata jumlah daun selengkapnya disajikan pada Tabel 6. Pada umur 30 HSS, rata-rata jumlah daun terbanyak terdapat ada akar pakis $100 \%$, yaitu 9,81, tetapi karena dari hasil uji statistik tidak ada perbedaan signifikan antar perlakuan, maka perlakuan yang diberikan sama 
baiknya. Kandungan bahan organik pada media tanam 100\% akar pakis lebih tinggi sehingga tidak mengalami kendala dalam penyediaan air, udara, dan unsur hara bagi tanaman untuk pertumbuhannya. Sebagaimana dikemukakan Muslihat (2003), bahwa kandungan bahan organik dalam media yang cukup tinggi akan membuat kondisi media menjadi kondusif untuk pertumbuhan akar tanaman. Seluruh komponen tersebut mampu memacu proses fotosintesis secara optimal.

Tabel 6. Pengaruh media tanam terhadap rata-rata jumlah daun bibit Eucalyptus pellita umur 30 HSS

\begin{tabular}{cc}
\hline Media Tanam & Jumlah Daun (Helai) \\
\hline Mo (akar pakis 100\%) & 9,81 \\
M1 (akar pakis 90\% + arang sekam 10\%) & 9,28 \\
M2 (akar pakis 80\% + arang sekam 20\%) & 8,61 \\
M3 (akar pakis 70\% + arang sekam 30\%) & 9,01 \\
M4 (akar pakis 60\% + arang sekam 40\%) & 9,87 \\
\hline
\end{tabular}

Jumlah Daun Umur 45 Hari Setelah Sapih (HSS)

Hasil analisis keragaman, menunjukkan bahwa perlakuan media tanam akar pakis dan arang sekam berpengaruh tidak nyata terhadap rata-rata jumlah daun bibit $E$. pellita pada umur 45. Pengaruh media tanam akar pakis terhadap rata-rata jumlah daun bibit selengkapnya disajikan pada Tabel 7 .

Tabel 7. Pengaruh media tanam terhadap rata-rata jumlah daun bibit Eucalyptus pellita umur 45 HSS

\begin{tabular}{cc}
\hline Media Tanam & Jumlah Daun (Helai) \\
\hline M0 (akar pakis 100\%) & 12,05 \\
M1 (akar pakis 90\% + arang sekam 10\%) & 11,01 \\
M2 (akar pakis 80\% + arang sekam 20\%) & 11,08 \\
M3 (akar pakis 70\% + arang sekam 30\%) & 11,20 \\
M4 (akar pakis 60\% + arang sekam 40\%) & 11,36 \\
\hline
\end{tabular}

Pada umur 45 HSS, rata-rata jumlah daun terbanyak terdapati pada akar pakis $100 \%$, yaitu 12,05, tetapi karena dari hasil uji statistik tidak ada perbedaan signifikan antar perlakuan, maka perlakuan yang diberikan sama baiknya. Hal ini, disebabkan karena adanya akar pakis sehingga kondisi kelembaban media tanam dapat terjaga serta sirkulasi udara berjalan dengan baik. Media tanam akar pakis memiliki kandungan unsur nitrogen sehingga kebutuhan nitrogen bagi pertumbuhan organ-organ bibit dapat tersedia. Sebagaimana dikemukakan Purwanto, dkk. (2014), mengemukakan bahwa unsur hara yang berpengaruh terhadap pertumbuhan dan perkembangan daun adalah Nitrogen $(N)$. Konsentrasi Nitrogen $(\mathrm{N})$ yang tinggi menghasilkan daun yang lebih besar dan banyak, karena Nitrogen $(\mathrm{N})$ yang tersimpan merupakan unsur penting dalam protoplasma, maka pada setiap perlakuan tingkat kandungan Nitrogen $(N)$ yang paling tinggi dapat memperoleh tingkat pertumbuhan jumlah daun yang paling optimal.

\section{Jumlah Daun Umur 60 Hari Setelah Sapih (HSS)}

Hasil analisis keragaman, menunjukkan bahwa perlakuan media tanam akar pakis dan arang sekam berpengaruh tidak nyata terhadap rata-rata jumlah daun bibit $E$. pellita pada umur 60. Pengaruh media tanam akar pakis terhadap jumlah daun selengkapnya disajikan pada Tabel 8. 
Tabel 8. Pengaruh media tanam terhadap rata-rata jumlah daun bibit Eucalyptus pellita umur 60 HSS

\begin{tabular}{lr}
\hline Media Tanam & Jumlah Daun B \\
\hline Mo (akar pakis 100\%) & 14,86 \\
M1 (akar pakis $90 \%$ + arang sekam 10\%) & 13,34 \\
M2 (akar pakis 80\% + arang sekam 20\%) & 13,54 \\
M3 (akar pakis 70\% + arang sekam 30\%) & 13,32 \\
M4 (akar pakis 60\% + arang sekam 40\%) & 11,81 \\
\hline Pada umur 60 HSS, rata-rata jumlah daun terbanyak terdap
\end{tabular}

14,86

13,34

13,54

Pada umur $60 \mathrm{HSS}$, rata-rata jumlah daun terbanyak terdapat pada akar pakis $100 \%$, yaitu 14,86 helai, tetapi karena dari hasil uji statistik tidak ada perbedaan signifikan antar perlakuan, maka perlakuan yang diberikan sama baiknya. Media tanam akar pakis dapat menyediakan dan menjaga suhu lingkungan media perakaran bibit. Sejalan dengan Mahleni (2007), bahwa pada pembibitan, perbedaan suhu siang dan malam yang besar akan memacu pertunasan. Sebagaimana dikemukakan Purwanto dkk. (2014), bahwa batang pakis mengandung unsur Nitogen $(N)$, Karbon $(C)$, Hidrogen $(H)$, dan Silika yang dibutuhkan untuk pertumbuhan tanaman.

\subsection{Diameter Batang $(\mathrm{Cm})$}

Hasil analisis keragaman, menunjukkan bahwa perlakuan media tanam akar pakis dan arang sekam berpengaruh tidak nyata terhadap diameter batang bibit $E$. pellita. Pengaruh media tanam akar pakis terhadap diameter batang selengkapnya disajikan pada Tabel 9.

Tabel 9. Pengaruh media tanam terhadap rata-rata diameter batang bibit Eucalyptus pellita

\begin{tabular}{lr}
\hline Media Tanam & Diameter Batan \\
\hline Mo (akar pakis 100\%) & 3,14 \\
M1 (akar pakis 90\% + arang sekam 10\%) & 2,60 \\
M2 (akar pakis 80\% + arang sekam 20\%) & 2,62 \\
M3 (akar pakis 70\% + arang sekam 30\%) & 2,47 \\
M4 (akar pakis 60\% + arang sekam 40\%) & 2,28
\end{tabular}

Rata-rata diameter terbesar terdapat pada akar pakis $100 \%$, yaitu $3,14 \mathrm{~cm}$, tetapi karena dari hasil uji statistik tidak ada perbedaan signifikan antar perlakuan, maka perlakuan yang diberikan sama baiknya. Media tanam akar pakis memiliki tingkat kerapatan yang rendah sehingga akar bibit dapat berkembang dan menyerap unsur hara. Sebagaimana dikemukakan Hardjowigeno (2007), bahwa kerapatan lindak (bulk density) merupakan kerapatan media, makin tinggi nilai kerapatan lindaknya makin padat media tersebut, mengakibatkan semakin sulit untuk ditembus akar tanaman. Unsur hara yang terkandung didalam media tanam yang 100\% akar pakis memiliki paling banyak unsur hara yaitu Hidrogen $(\mathrm{H})$ dan Nitrogen $(\mathrm{N})$, sehingga berbeda dengan perlakuan media tanam lainnya yang hanya mengandung Hidrogen $(H)$ dan Nitrogen $(N)$ dalam konsentrasi yang lebih kecil. Menurut Purwanto dkk. (2014) faktor lingkungan yang besar pengaruhnya terhadap pemanjangan batang adalah suhu dan intensitas cahaya. Pemanjangan batang terpacu jika tanaman dibutuhkan pada tempat dan intensitas cahaya rendah. Laju pemanjangan batang berbeda antar spesies dan dipengaruhi oleh lingkungan dimana tanaman tersebut tumbuh. 


\section{$4 \quad$ Kesimpulan}

Berdasarkan hasil penelitian pengaruh media tanam terhadap perkecambahan dan pertumbuhan bibit E. pellita menunjukkan bahwa media tanam akar pakis $100 \%$ menunjukkan kinerja pertumbuhan tertinggi, akan tetapi berdasarkan uji statistik yang menunjukkan perbedaan tidak nyata, dapat disimpulkan bahwa kombinasi media tanam akar pakis dan arang memiliki kinerja yang sama.

\section{Daftar Pustaka}

Fahmi, Z. I. 2014. Media Tanam Sebagai Faktor Eksternal yang Mempengaruhi Pertumbuhan Tanaman. Balai Besar Perbenihan dan Proteksi Tanaman Perkebunan. Surabaya.

Gardner, F.P., Pearce R.B, dan Mitchell, R. L. diterjemahkan oleh Susilo, H dan Subiyanto. 1991. Fisiologi Tanaman Budidaya. Penerbit Universitas Indonesia (UI Press). Jakarta.

Hanafiah, K. A. 2010. Rancangan Percobaan. Universitas Sriwijaya. Palembang.

Hardjowigeno, S. 2007. Ilmu Tanah. Akademika Presindo. Jakarta.

Kuswanto, H. 1996. Dasar-dasar Teknologi Produksi dan Sertifikasi Benih. Edisi ke-1. ANDI. Yogyakarta. HIm 190.

Leksono, B. 2001. Potensi Eucalyptus pellita untuk Pembangunan Hutan tanaman Industri (HTI) dan pengembangan Program Pemuliaan Pohon. Makalah Simposium Nasional dan Kongres IV PERIPI. P3BPTH. Yogyakarta

Mahleni, R. 2007. Pengaruh Pupuk Organik Cair dan Agensia Hayati Terhadap Pencegahan Penyakit Antraknosa (Colletotrichum gloeosporiodies (Penz) Sacc) Pada Pembibitan Tanaman Kakao (Theobroma cacao L). Medan. Departemen IImu Hama dan Penyakit Tumuhan. Faperta Universitas Sumatera Utara.

Muliawan, L. 2009. Pengaruh Media Semai Terhadap Pertumbuhan Pelita (Eucalyptus pellita F. Muell). Skripsi. Fakultas Kehutanan. Institut Pertanian Bogor. Bogor.

Muslihat, L. 2003. Teknik Percobaan Takaran Pupuk Kandang Pada Pembibitan Abaca. Buletin Teknik Pertanian 8(1).

Purwanto, J., Asngad, A., Suryani, T. 2012. Pengaruh Media Tanam Arang Sekam dan Batang Pakis Terhadap Pertumbuhan Cabai Merah Keriting (Capsicum annum L) Ditinjau Dari Intensitas Penyiraman Air Kelapa. Fakultas Keguruan dan IImu Pendidikan Biologi. Universitas Muhammadiyah. Semarang.

Putri, K. P., dan Djam'an, D. F. 2004. Peranan Manajemen Persemaian Dalam Upaya Penyiapan Bibit Berkualitas. Jurnal Info Benih. 9(1):13-26. 